Parra-Montesinos, G. J., Wight, J. K., Kopczynski, C., Lequesne, R. D., Setkit, M., Conforti, A., and Ferzli, J. (2017).

"Elimination of Diagonal Reinforcement in Earthquake-Resistant Coupling Beams through Use of Fiber-Reinforced Concrete."

SP-313: Proceedings of the First ACl and JCl Joint Seminar: Design of Concrete Structures Against Earthquake and Tsunami

Disasters, Special Publication of the American Concrete Institute, Farmington Hills, MI.

\title{
Elimination of Diagonal Reinforcement in Earthquake-Resistant Coupling Beams through Use of Fiber-Reinforced Concrete
}

\section{G.J. Parra-Montesinos ${ }^{1}$, J.K. Wight ${ }^{2}$, C. Kopczynski ${ }^{3}$, R.D. Lequesne ${ }^{4}$, M. Setkit $^{5}$, A. Conforti ${ }^{6}$, and J. Ferzli ${ }^{7}$}

Synopsis: The design of reinforced concrete coupling beams in regions of high seismicity typically includes the use of diagonal bars designed to resist the entire shear demand, along with closely spaced transverse reinforcement to provide concrete confinement and diagonal bar support. While results from experimental investigations indicate that this design leads to stable behavior under large displacement reversals, the required reinforcement detailing is labor intensive and time consuming. One alternative that has been proven successful to simplify reinforcement detailing in coupling beams is the addition of discontinuous, deformed steel fibers to the concrete. Test results indicate that elimination of diagonal reinforcement, along with substantial reductions in confinement reinforcement over most of the beam span, are possible in coupling beams with span-to-depth ratios greater than or equal to approximately 2.2 when a tensile strain-hardening fiber reinforced concrete is used. Given the advantages of eliminating diagonal reinforcement in coupling beams, this new design was incorporated in high-rise structures in the State of Washington, USA, starting in the early 2010s. In this paper, a brief summary of relevant experimental results and the implementation of fiber reinforced concrete coupling beams in high-rise earthquake-resistant construction is provided.

Keywords: Coupled walls, steel fibers, link beams, shear, drift capacity

\section{INTRODUCTION}

Structural walls connected by beams are often used for lateral strength and stiffness in medium- and highrise structures located in regions of high seismicity. These beams, referred to as coupling or link beams, have span-to-depth ratios typically ranging between 2.0 and 3.5, which makes them shear-critical elements. Further, because the coupling beam span is substantially smaller than the distance between the neutral axes of the walls being connected, rotation demands in these coupling beams can be several times the wall drift. The combination of a low span-to-depth ratio and large shear and drift reversals poses significant challenges in the design of coupling beams, given that the shear strength and rotation capacity of beams designed as those of Special Moment Resisting Frames (ACI Committee 318, 2014) are often not sufficient for their use as coupling beams (Naish et al., 2009).

${ }^{1}$ C.K. Wang Professor, Dept. of Civil and Environ. Eng., University of Wisconsin-Madison, WI 53706, USA

${ }^{2}$ Frank E. Richart, Jr. Collegiate Professor, Dept. of Civil and Environ. Eng., Univ. of Michigan, Ann Arbor, MI 48109-2125, USA

${ }^{3}$ CEO, Cary Kopczynski \& Co., Bellevue, WA 98004, USA

${ }^{4}$ Assistant Professor, Dept. of Civil, Environ. \& Arch. Eng., University of Kansas, Lawrence, KS 66045, USA

${ }^{5}$ Lecturer, Institute of Engineering and Resources, Walailak University, Thailand

${ }^{6}$ Postdoctoral Fellow, Dept. of Civil, Arch., Environ., Land Planning Eng. and Mathematics, Univ. of Brescia , Italy

${ }^{7}$ Principal, Cary Kopczynski \& Co., Bellevue, WA 98004, USA 
In the late 1960s and early 1970s, researchers in Argentina (Luisoni et al.,1970) and New Zealand (Paulay and Binney, 1974) investigated the use of diagonal reinforcement as a means to improve the behavior of coupling beams. Current design provisions in the ACI Building Code (ACI Committee 318, 2014) for diagonally reinforced coupling beams are primarily based on research by Paulay and collaborators (Paulay, 1986). These provisions require diagonal reinforcement to be designed to resist the entire shear demand. In addition, transverse reinforcement similar to that required for columns in Special Moment Resisting Frames must be provided to confine either each group of diagonal bars or the entire coupling beam. Figure 1 shows a typical diagonally reinforced coupling beam.

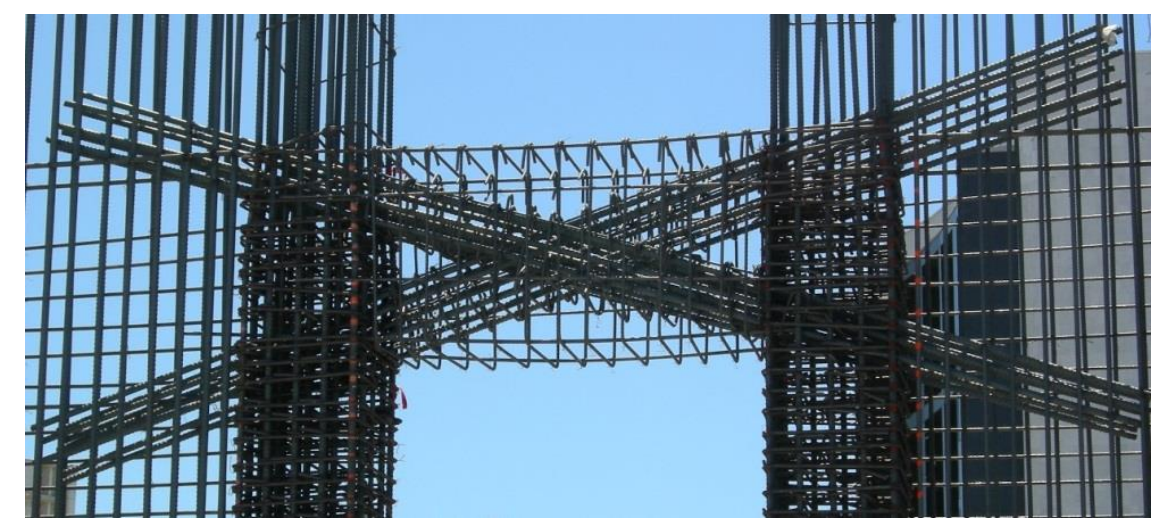

Figure 1: Diagonally reinforced earthquake-resistant coupling beam

Recognizing the construction difficulties involved with the use of diagonal reinforcement in coupling beams, researchers at the University of Michigan and the University of Wisconsin-Madison have extensively investigated the possibility of simplifying reinforcement detailing in coupling beams through the use of tensile strain-hardening fiber reinforced concrete, typically referred to as High-Performance Fiber Reinforced Concrete (HPFRC) (for example Canbolat, Parra-Montesinos and Wight, 2005; ParraMontesinos et al., 2011; 2014). The tension and compression ductility of these materials allows substantial reductions in reinforcement used for shear resistance, confinement and lateral bar support without compromising drift capacity. As will be discussed next, elimination of diagonal bars is even possible for coupling beams with span-to-depth ratios greater than or equal to approximately 2.2 .

\section{BEHAVIOR OF HPFRC COUPLING BEAMS WITHOUT DIAGONAL BARS}

The behavior of HPFRC coupling beams without diagonal reinforcement is illustrated through the results from tests of three coupling beam specimens subjected to large drift reversals. The specimens had spanto-depth ratios of 2.2, 2.75 and 3.3, covering most cases in current practice. Specimens were tested under fully-reversed cycles of increasing displacement magnitude using a setup that imposed double-curvature bending and restrained axial elongation (see Reference [5]). Figure 2 shows the reinforcement detailing for the coupling beam specimen with aspect ratio of 2.75 , which is representative of that used in the other two coupling beams. Flexural reinforcement was selected such that the peak shear force corresponded to an average stress close to the upper limit in ACI $318-14\left(0.83 \sqrt{f_{c}^{\prime}}, \mathrm{MPa} ; 10 \sqrt{f_{c}^{\prime}}\right.$, psi). Therefore, the behavior of coupling beams subjected to lower shear stresses should be at least as good, arguably better, than that of the test coupling beams.

Although specimens were cast at different times, each used the same HPFRC mixture having the following proportions by weight: 1:0.875:2.2:1.2:0.8:0.005:0.038 for cement:fly ash:sand:course aggregate:water:high-range water reducing agent:viscosity modifying agent. The fiber reinforced concrete 
Elimination of Diagonal Reinforcement in Earthquake-Resistant

Coupling Beams through Use of Fiber-Reinforced Concrete

mixture used included $30 \mathrm{~mm}$ (1.2 in.) long, $0.38 \mathrm{~mm}(0.015 \mathrm{in}$.) diameter hooked steel fibers with a specified tensile strength of $2300 \mathrm{MPa}(330 \mathrm{ksi})$. The fiber volume fraction was the same for all three specimens (1.5\%). Course aggregate consisted of crushed limestone with a maximum size of $13 \mathrm{~mm}(1 / 2$ in. ). Concrete cylinder compressive strength at test day was $63 \mathrm{MPa}$ (9100 psi) for the specimen with aspect ratio of 2.2, and $68 \mathrm{MPa}(9900 \mathrm{psi})$ for the specimens with apect ratio of 2.75 and 3.3.

HPFRC prisms with dimensions of 150 by 150 by $500 \mathrm{~mm}$ ( 6 by 6 by 20 in.) were tested under thirdpoint bending in accordance with ASTM C1609. Typical results are shown in Figure 3 as a plot of equivalent bending stress versus midspan deflection responses, where equivalent bending stress refers to the tensile stress calculated at the bottom of the section assuming linear elastic behavior and uncracked section properties. Peak strengths typcially exceeded the first cracking strength by approximately $30 \%$, with the peak strength occurring, on average, at a midspan deflection of $0.5 \mathrm{~mm}$ (0.02 in.). More detailed results are available in Setkit (2012).

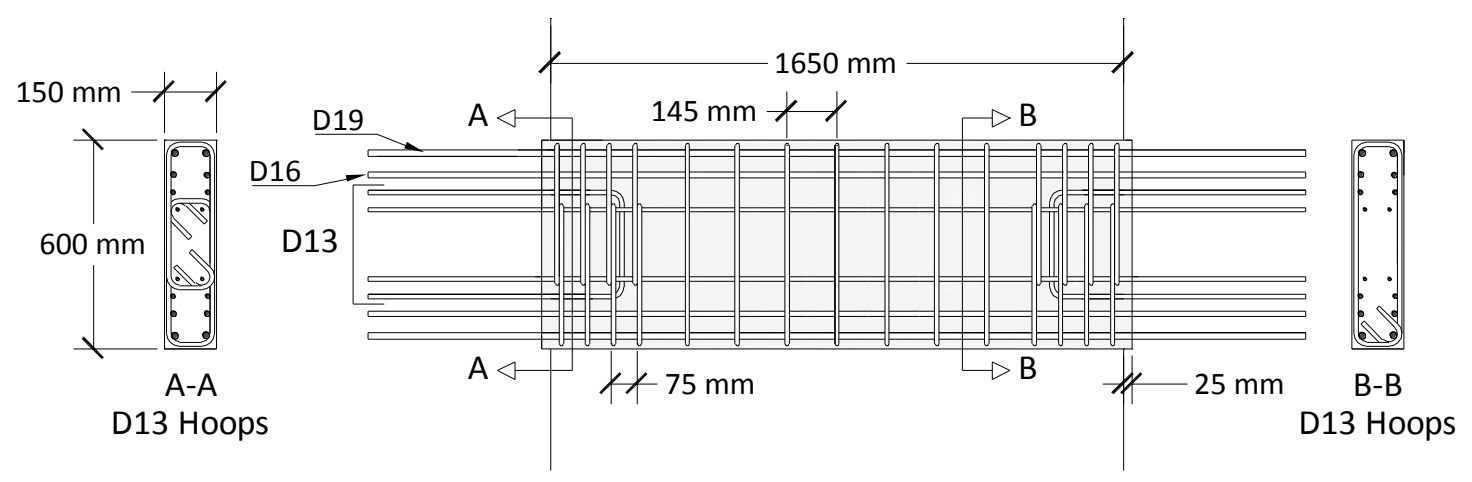

Figure 2: $\quad$ Reinforcement details for test coupling beam with span-to-depth ratio of 2.75

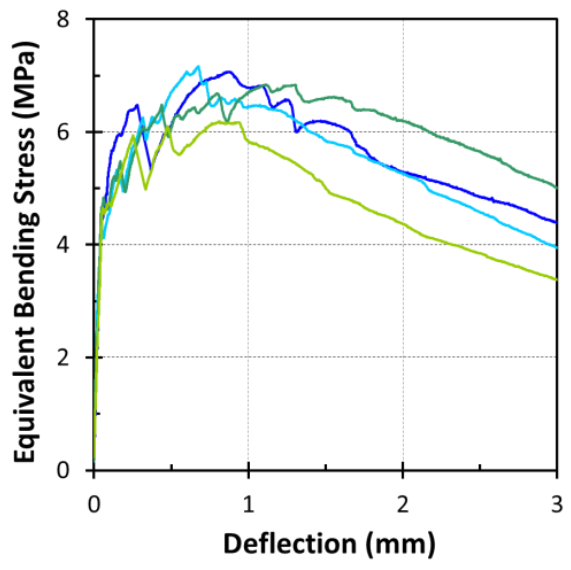

Figure 3: $\quad$ Typical test results from HPFRC specimens tested under third-point bending.

Another aspect investigated was the use of precast concrete coupling beams as an alternative to cast-inplace concrete, as this may prove beneficial when use of HPFRC materials is limited to the coupling beam (and reinforced concrete without fibers is used in the walls). In Fig. 2, the shaded region represents the precast portion of the beam specimen, which ends approximately $25 \mathrm{~mm}(1 \mathrm{in}$.) into the wall edge. The flexural reinforcement extends beyond the precast portion and is fully developed into the walls. The cold joint between the precast coupling beam and the wall deserves special attention, given the fact that large inelastic rotations may lead to the opening of a wide gap at this joint, trigerring a premature sliding shear 
failure. To protect this joint, intermediate reinforcement is used that causes the flexural strength of the coupling beam to slightly exceed the maximum expected demand at its connection with the wall. Because the ratio of flexural demand to capacity is then highest where intermediate reinforcement is terminated within the beam span, inelastic deformations develop within the HPFRC coupling beam and away from the cold joint. Use of the same intermediate reinforcement is also recommended for cast-in-place construction, as there is likely to be a cold joint between the wall and coupling beam concrete. As reported previously [4], this detailing causes most inelastic deformations to occur within the span of the HPFRC coupling beam and away from the joint.

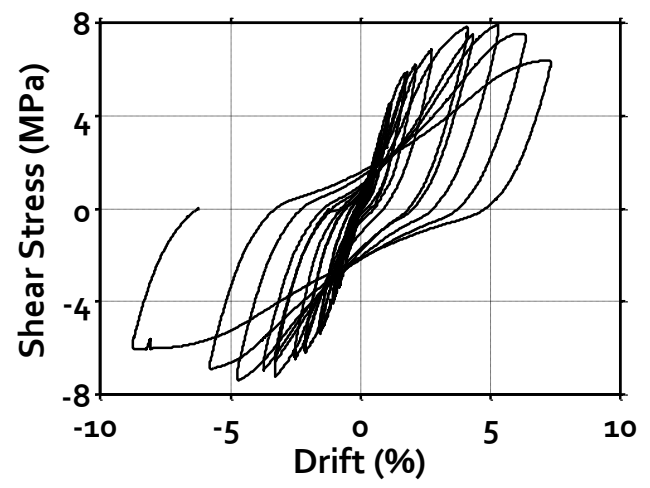

a) Span-to-depth ratio $=\mathbf{2 . 2}$

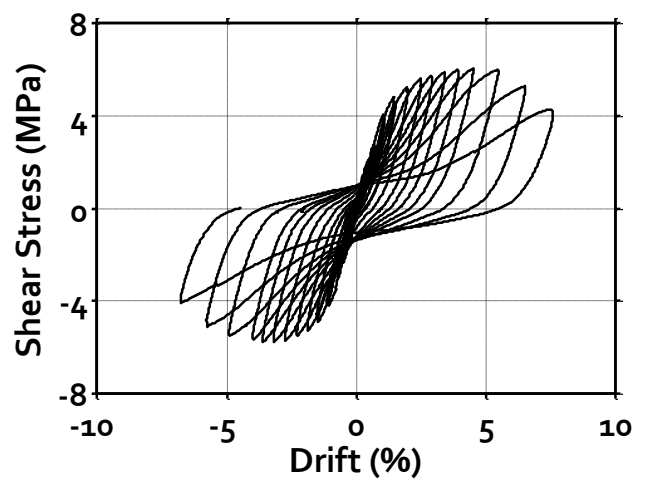

b) Span-to-depth ratio $=\mathbf{2 . 7 5}$

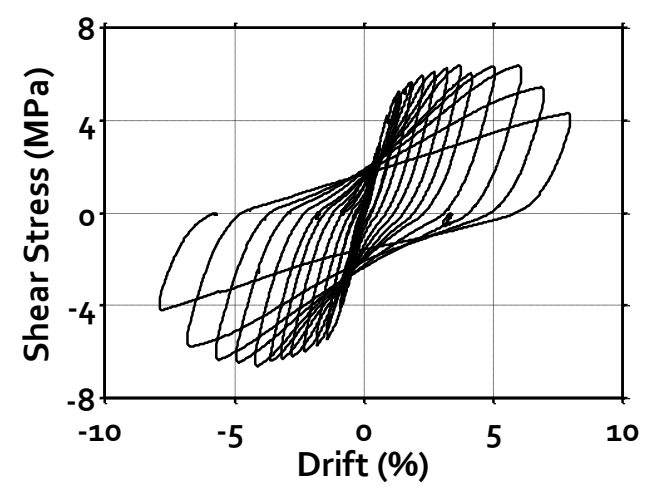

c) Span-to-depth ratio $=3.3$

Figure 3: $\quad$ Shear stress versus drift behavior for test specimens 
Figure 3 shows the average shear stress versus drift response for the three coupling beam specimens. Average shear stress is equal to the applied shear divided by the cross-sectional area of the coupling beam, while drift refers to the average chord rotation. In terms of $\sqrt{f_{c}^{\prime}}$, the peak average shear stress sustained by the three coupling beams was $1.0,0.75$, and $0.81 \sqrt{f_{c}^{\prime}}, \mathrm{MPa}\left(12.0,9.0\right.$, and $9.7 \sqrt{f_{c}^{\prime}}$, psi) for coupling beam aspect ratios of 2.2, 2.75 and 3.3, respectively. From the hysteresis shown in Fig. 3, it can be seen that the test coupling beams exhibited drift capacities in excess of 5\%, even though these were subjected to shear stresses comparable to the maximum limit in ACI 318-14 (drift capacity is defined as the largest drift cycle completed before a $20 \%$ loss in lateral strength). As expected, the more slender coupling exhibited the largest drift capacity, approximately 7\%. All three specimens exhibited a dense array of diagonal and flexural cracks, which allowed a more uniform distribution of deformation as compared to reinforced concrete construction. For the particular case of the coupling beam with a span-todepth ratio of 3.3, damage was considered minor up to a drift of approximately 5\% (Fig. 4), indicating that these coupling beams possess a high drift threshold below which repairs would not likely be needed.

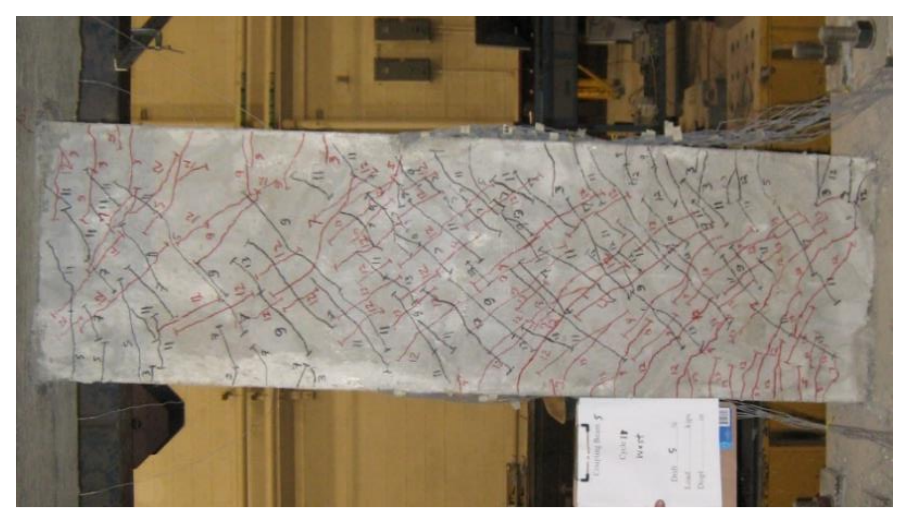

Figure 4: $\quad$ Coupling beam with span-to-depth ratio of 3.3 at $5 \%$ drift

\section{INCORPORATION OF HPFRC COUPLING BEAMS IN HIGH-RISE CONSTRUCTION}

The advantages offered by the elimination of diagonal bars and major reductions in transverse bar-type reinforcement has attracted the attention of structural engineers and contractors. The structural design firm Cary Kopczynski \& Co has incorporated HPFRC coupling beams without diagonal bars in the design of high-rise buildings. One such building is The Martin, a 24-story core-wall structure located in the city of Seattle, WA, USA (Fig. 5). In this structure, HPFRC coupling beams with a $76 \mathrm{x} 46 \mathrm{~cm}(30 \mathrm{x} 18 \mathrm{in}$.) cross section and span-to-depth ratio of 2.8 were used from the $12^{\text {th }}$ level up. Design shear stresses in the coupling beams ranged from $0.33 \sqrt{f_{c}{ }^{\prime}}$ to $0.71 \sqrt{f_{c}{ }^{\prime}}, \mathrm{MPa}\left(4 \sqrt{f_{c}{ }^{\prime}}\right.$ to $8.5 \sqrt{f_{c}{ }^{\prime}}$, psi). Transverse reinforcement at the ends of the beam (within a distance from the ends equal to half the overall beam depth) satisfied Building Code (ACI 318-14) requirements for confinement reinforcement in columns of special moment frames. Over the remainder of the beam span, transverse reinforcement was selected so as to resist the shear demand exceeding the assumed contribution from the HPFRC material, taken as $0.29 \sqrt{f_{c}{ }^{\prime}}, \mathrm{MPa}\left(3.5 \sqrt{f_{c}{ }^{\prime}}, \mathrm{psi}\right)$.

The fiber reinforced concrete coupling beams in The Martin were cast-in-place as opposed to precast, as originally tested. Fiber type and dosage were kept the same as in the test program. The fiber reinforced concrete was delivered in ready-mix concrete trucks and cast using a bucket and crane operation (Fig. 6). To verify that adequate fiber distribution could be achieved, small samples were cast and cut after hardening of concrete for visual inspection. Specified concrete strength ranged between 41 and $69 \mathrm{MPa}$ $(6,000$ and $10,000 \mathrm{psi})$. 
Fiber reinforced concrete coupling beams are also being used in the 240,000 $\mathrm{m}^{2}\left(2.6\right.$ million $\left.\mathrm{ft}^{2}\right)$ Lincoln Square Expansion Project in the city of Bellevue, WA, USA (currently under construction). This project features two high-rise towers (41 and 31 stories plus six levels below grade) designed by Cary Kopczynski \& Co. Use of SFRC in coupling beams on this project resulted in up to a $40 \%$ reduction in reinforcing steel and approximately 30\% net cost savings compared to traditional coupling beam construction. All coupling beams have a span-to-depth ratio of 3.0, with cross section of either $76 \times 91 \mathrm{~cm}$ ( $30 \times 36$ in.) or $91 \times 61 \mathrm{~cm}$ ( $36 \times 24$ in.). Expected peak shear stress in the coupling beams is $0.62 \sqrt{f_{c}{ }^{\prime}}$, $\operatorname{MPa}\left(7.4 \sqrt{f_{c}{ }^{\prime}}, \mathrm{psi}\right)$ and transverse reinforcement is provided such that the demand in the fiber reinforced concrete is kept below $0.29 \sqrt{f_{c}{ }^{\prime}}$, MPa $\left(3.0 \sqrt{f_{c}{ }^{\prime}}, \mathrm{psi}\right)$. As in The Martin, ready-mix fiber reinforced concrete is being used, which is cast using a crane and bucket operation.

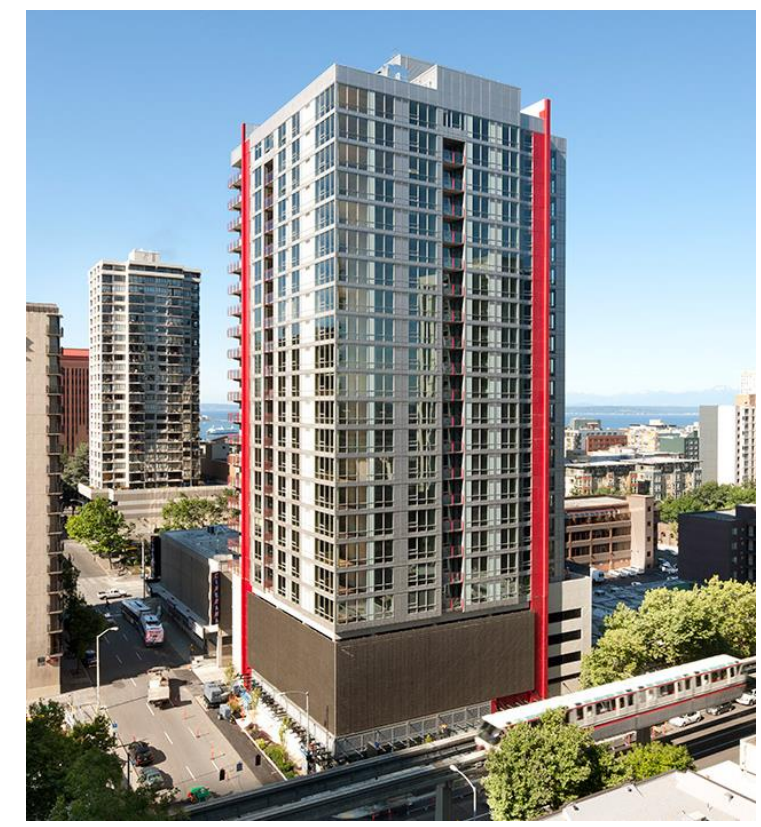

Figure 5: The Martin; a core-wall structure with HPFRC coupling beams in the city of Seattle, WA, USA

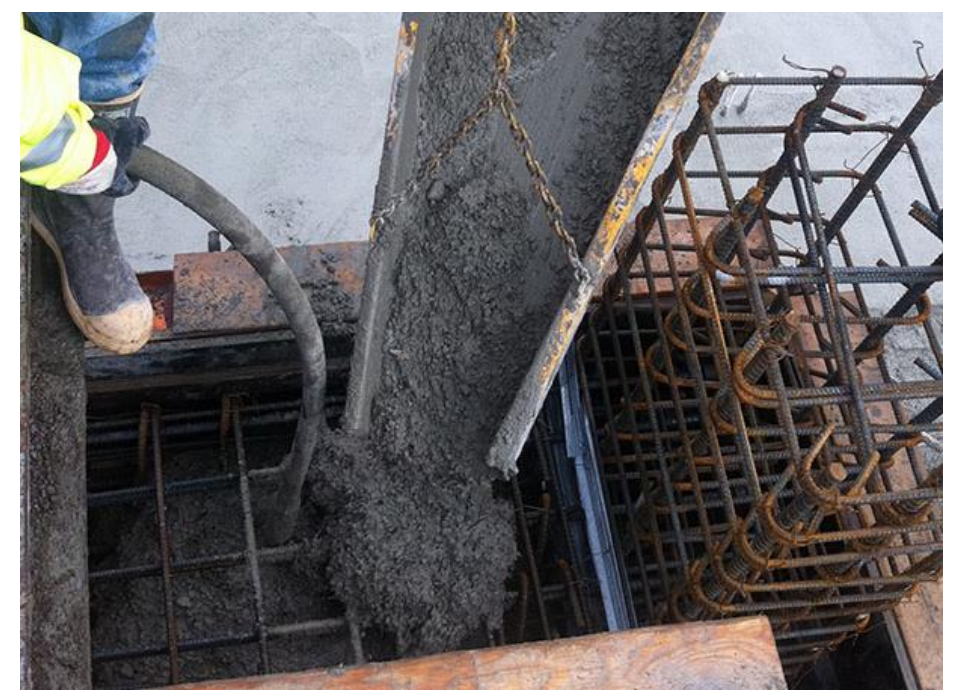

Figure 6: $\quad$ Casting of fiber reinforced concrete coupling beam in The Martin building 
Elimination of Diagonal Reinforcement in Earthquake-Resistant

Coupling Beams through Use of Fiber-Reinforced Concrete

\section{CONCLUSIONS}

Test results indicate that the design and construction of earthquake-resistant coupling beams can be significantly simplified through the use of a tensile strain-hardening fiber reinforced concrete. The tension and compression ductility of the fiber reinforced concrete allows total elimination of diagonal bars, as well as significant reductions in bar-type transverse reinforcement used for confinement and bar support. Test coupling beams subjected to average shear stresses comparable to the maximum limit in the ACI 318-14 Code exhibited drift capacities in excess of $5 \%$.

Given the advantages provided by the elimination of diagonal bars in coupling beams, fiber reinforced concrete coupling beams without diagonal reinforcement have been used since the early $2010 \mathrm{~s}$ in the State of Washington, USA. Field experience has shown the feasibility of using ready-mix fiber reinforced concrete cast following a crane and bucket operation.

\section{ACKNOWLEDGMENTS}

Results presented herein are from research funded by NSF Grant \#CMS 0530383 and Bekaert Corporation. It was a part of the NEES research program. The ideas and conclusions expressed are those of the writers, and do not necessarily represent the views of the sponsors.

\section{REFERENCES}

1. ACI Committee 318 (2014). Building Code Requirements for Structural Concrete (ACI 318-14) and Commentary (ACI 318R-14), American Concrete Institute, Farmington Hills, MI, 519 pp.

2. Luisoni, C. J., Somenson, H. M., and Ungaro, M. A. (1970). "Verificación Experimental de un Cálculo Plástico y Otro Elástico de una Pared de Corte," IV Simposio Panamericano de Estructuras, V. 5, Oct. 1970, pp. 230-286. (in Spanish)

3. Naish, D., Wallace, J.W., Fry, J.A., and Klemencic, R. (2009). "Reinforced Concrete Link Beams: Alternative Details for Improved Construction," UCLA-SGEL Report 2009-06, Structural \& Geotechnical Engineering Laboratory, University of California at Los Angeles, 103 pp.

4. Parra-Montesinos, G.J., Wight, J.K., Lequesne, R., and Setkit, M. (2011). "A Summary of Ten Years of Research on HPFRC Coupling Beams," Proceedings of the $6^{\text {th }}$ Workshop on High-Performance Fiber Reinforced Cement Composites, Ann Arbor, June 20-22, 2011, G.J. Parra-Montesinos, H.W. Reinhardt, and A.E. Naaman Editors, Springer.

5. Parra-Montesinos, G.J., Wight, J.K., Kopczynski, C., Lequesne, R., Setkit, M., Conforti, A., and Ferzli, J. (2014). "High-Performance Fiber Reinforced Concrete Coupling Beams: From Research to Practice," Proceedings of the $10^{\text {th }}$ National Conference in Earthquake Engineering, Earthquake Engineering Research Institute, Anchorage, AK, 2014.

6. Paulay, T., and Binney, J.R. (1974). "Diagonally Reinforced Coupling Beams," Special Publication SP-42, American Concrete Institute, Detroit, Michigan, pp. 579-598.

7. Paulay, T. (1986). "The Design of Ductile Reinforced Concrete Structural Walls for Earthquake Resistance," Earthquake Spectra, Vol. 2, No. 4, pp. 783-823.

8. Setkit, M. (2012). Seismic Behavior of Slender Coupling Beams Constructed with High-Performance Fiber-Reinforced Concrete. PhD Dissertation. The University of Michigan. 
Parra-Montesinos et al. 